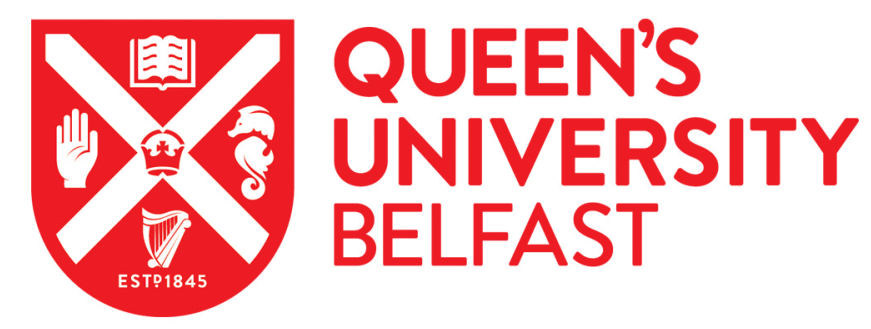

\title{
A systematic review of consumer perceptions of food and authenticity: A European perspective
}

Kendall, H., Clark, B., Rhymer, C., Kuznesof, S., Hajšlová, J., Tomaniova, M., Brereton, P., \& Frewer, L. (2019). A systematic review of consumer perceptions of food and authenticity: A European perspective. Trends in Food Science and Technology, 94, 79. https://doi.org/10.1016/j.tifs.2019.10.005

\section{Published in:}

Trends in Food Science and Technology

\section{Document Version:}

Peer reviewed version

Queen's University Belfast - Research Portal:

Link to publication record in Queen's University Belfast Research Portal

\section{Publisher rights}

(c) 2019 Elsevier Ltd. All rights reserved.

This manuscript version is made available under the CC-BY-NC-ND 4.0 license http://creativecommons.org/licenses/by-nc-nd/4.0/,which permits distribution and reproduction for non-commercial purposes, provided the author and source are cited.

\section{General rights}

Copyright for the publications made accessible via the Queen's University Belfast Research Portal is retained by the author(s) and / or other copyright owners and it is a condition of accessing these publications that users recognise and abide by the legal requirements associated with these rights.

Take down policy

The Research Portal is Queen's institutional repository that provides access to Queen's research output. Every effort has been made to ensure that content in the Research Portal does not infringe any person's rights, or applicable UK laws. If you discover content in the Research Portal that you believe breaches copyright or violates any law, please contact openaccess@qub.ac.uk. 
1 Acknowledgements

2 This research was funded through the 7th Framework Programme of the European Union as part of the

\section{$7 \quad 1 \quad$ Background}

$8 \quad 1.1$ What is food fraud

9 Food fraud involves 'the deliberate and intentional substitution, addition, tampering, or misrepresentation of food, food ingredients, or packaging; or false or misleading statements made about a product for economic gain' (Spink \& Moyer, 2011). A joint Europol-Interpol operation (OPSON) in 2017 reported that 9,800 tonnes, 26.4 million litres and 13 million items of counterfeited and potentially harmful food and drink products were seized from across 21 European Union member states, with an estimated value of 230 million Euros (Europol, 2017). These fraudulent practices are perpetrated by a range of food chain actors including; criminal gangs that infiltrate legitimate food chains, and legitimate actors that abuse or misuse their position within the food production system (Brooks, Elliott, Spence, Walsh, \& Dean, 2017; Lord, Flores Elizondo, \& Spencer, 2017; Spink \& Moyer, 2011; van Ruth, Huisman, \& Luning, 2017). However, given that fraudsters will seek to avoid detection and prosecution, it is difficult to estimate the true magnitude of fraudulent practices within local, national and pan-European food supply chains.

It is accepted that fraudulent activity in the food system undermines the integrity of the European food system as a whole, partly due to stakeholder (including consumer) perceptions that consumer protection measures are inadequate (Premanandh, 2013). However, the impact on European consumers' perceptions and attitudes to food integrity and safety has not, to date, been systematically evaluated. This is relevant from the perspective of developing and implementing mitigation policies, and predicting and explaining consumers' self-protective behaviours in relation to food fraud.

\subsection{Food fraud in Europe}

While food fraud does not necessarily represent a risk to public or environmental health, instead negatively impacting food quality (e.g. the dilution of alcohol with water and/or ingredient or species substitution), undisclosed contaminants in food supply chains means that food safety risks may be linked to fraudulent food practices. For example, the 1981 Spanish toxic olive oil incident remains Europe's most serious food fraud case in terms of mortality and morbidity of affected consumers. Fuel oil intended for industrial use was sold by street vendors as "olive oil" for human consumption. The resulting toxic oil syndrome experienced by people ingesting the oil was linked to the 1,200 deaths and 20,000 
hospitalisations, with lasting health implications for the surviving consumers (Snellings, McMartin, Banton, Reitman, \& Klapacz, 2017). A more recent example of food poisoning fatalities caused by fraudulent food practices involved spirits adulterated with methanol which were sold in the Czech Republic, Poland and Slovenia in 2012, causing 38 fatalities in the Czech Republic and a further 4 fatalities in Poland (Zakharov et al., 2014).

However, not all fraudulent food practices are necessarily harmful to human health and instead represent a food or drink quality concern such as the dilution of spirits with water. The undisclosed identification of horsemeat in processed beef products in the UK and Republic of Ireland is one such example. Although potential health concerns regarding equine veterinary drug residues were voiced at the time of the incident, they were assessed as being very small (Regan et al., 2015). Instead, the high profile case highlighted problems associated with integrity and complexity of the beef supply chain in Europe (Barnett et al., 2016) which was already a focus of consumer concern following the occurrence of BSE in 1996 (Lynn. Frewer \& Salter, 2002). Specifically, this particular supply chain was one which consumers' expected to be highly regulated and inspected. In 2017, eggs in Belgium were found to be contaminated with the veterinary insecticide 'Fipronil', a chemical forbidden for use in animals in livestock production systems, but which had been deliberately used to reduce infestation in the layer supply chain. Affected eggs were identified for sale in 26 European member states and 45 countries worldwide (BBC News, 2017; European Commission, 2017b, 2017c).

Media reports about food fraud incidents across Europe have been collated since 2016 by the Knowledge Centre for Food Fraud and Quality, hosted by the European Commission's Joint Research Centre. A significant number of European incidents constituting fraud have been reported, associated with mislabelling, adulteration, counterfeiting or theft, during the period 2016-2018. Wine, spirits, olive oil, fish, meat, cheese, honey and herbs and spices represent the most commonly reported adulterated foods (European Commission, 2019). Italy appears to have the most media reported incidents. Potential explanations include Italy being extremely active in exposing and combatting fraud, and the high number of Protected Designation of Origin (PDO), Protected Geographical Indication (PGI) and Traditional Speciality Guaranteed (TSG) Italian food specialties recognized and protected by the European Union; products that often command premium prices making them attractive targets for fraudsters.

Although the number of European food fraud incidents is high, there is no evidence available to suggest the number of fraud incidents are increasing, although this possibility cannot be eliminated. However, the improved governance, detection and surveillance of food fraud may have increased the detection of food fraud incidents (European Commission, 2017a). 

compromised the safety, integrity and reputation of European food globally (Thankappan, 2016). In response, the European Union overhauled the governance of its food system and implemented sweeping regulatory reforms (e.g. EC Regulation 178/2002). The European food system is currently recognised internationally for its high levels of production quality, safety, animal welfare, and stringent regulatory standards that underpin European and global consumer confidence and trust in the safety of the foods (Nakyinsige, Man, \& Sazili, 2012). However, the 2013 horsemeat incident was the catalyst for the formation of additional, integrated notification and response mechanisms for dealing directly with the threat of food fraud, presumably prompting governance changes because of the pan- European scale of the incident. For example the EU Food Fraud Network (FFN)(European Commission, no date) was established in order to facilitate cross-border collaboration and information sharing regarding suspected intentional and economically motivated violations in Europe, and beyond, that may impact European supply chains and in so doing protect and re-build consumer confidence in the integrity of European food.

\subsection{Consumer perceptions and attitudes} From a consumer perspective, the study of food fraud is most appropriately addressed through the consideration of: 1) perceptions and attitudes linked to food safety; 2) perception of, and attitudes towards, food authenticity, and; 3) trust in institutions and experts.

Maintaining consumer confidence in food authenticity and the integrity of the food supply chain overall, will potentially circumvent the negative economic and societal effects associated with consumer concerns about the associated safety and integrity of food (De Jonge et al., 2004; European Commission, 2010). Food fraud events have been shown to negatively impact consumer confidence and trust in affected products, food chain actors and food systems (see, inter alia, (Frewer, Howard, Hedderley, \& Shepherd, 1996; Lobb, 2005). Given the complexity of modern food systems, food transactions are typically operationalised by organisations including primary producers, ingredient suppliers, food manufacturers, regulators and enforcement services, etc. Trust in these actors is referred to as institutional trust which is built and sustained by consumer perceptions that their actions and activities are robust, that there is transparency in operations (i.e. regulations and enforcement), and that there is effective communication with the public regarding consumer protection in relation to food.

Food chain actors use a range of signals to communicate their trustworthiness including effective knowledge exchange between stakeholders in industry, regulatory institutions and civil society organisations, and certification, packaging and labelling that support consumers evaluations of credence attributes such as product origin and production speciality claims, e.g. organic and fair trade claims (EI Benni et al., 2019; Grayson \& Martinec, 2004; Liu, Yannopoulou, Bian, \& Elliott, 2015). Relational trust 
such as farmer's markets or direct consumer-supplier relationships with local butchers. In situations where there has been a breach of trust, there has been a rise in the prominence of alternative food networks that are perceived by consumers as reducing the complexity of supply chains (Kendall et al., 2018; Lyon \& Porter, 2007; Zhang, Xu, Oosterveer, \& Mol, 2016). Trust in information sources may correlate with the extent to which consumers trust to food safety guarantees, information provided about food safety regulation, regulatory enforcement, or the efficacy of mitigation measures (see, inter alia, (Frewer et al., 2016; Hobbs \& Goddard, 2015)).

Food choices are a ubiquitous part of everyday life and consumers are required to continually make food consumption decisions without complete knowledge of a product's quality, safety or reliability. There is therefore, an inbuilt asymmetry to consumer trust. Trust allows consumers to act without complete knowledge of whether or not a food is risky to consume (Hansen, Holm, Frewer, Robinson, \& Sandøe, 2003; Luhmann, 2000).

\subsection{Authenticity}

Under some circumstances, (e.g. packaged products), the authenticity of food may not be easily observed, experienced or verified by consumers. It can only be evaluated through signalling cues provided by food manufacturers and regulators that indicate the authenticity attribute (Martinez \& Epelbaum, 2011) consumers therefore rely on the transparency and efficacy of regulatory enforcement, appropriate and proportionate mitigation measures, and their trust in food chain stakeholders and their production practices, as signals of food integrity (Meijboom, Visak, \& Brom, 2006). Traceability systems provide information about the history of a product and allow food to be traced and followed through a production chain. This enables the origin of a product and its journey through a given supply chain to be documented, and facilitates implementation of mitigation actions, e.g. product recalls, if a product is found to be non-compliant with quality or safety standards (Food Standards Agency, 2017; Spence, Stancu, Elliott, \& Dean, 2018; Van Rijswijk \& Frewer, 2012). Labelling and trade standards provide verifiable objective specifications and claims for authentication. Several studies have attempted to summarise different aspects of authenticity, such as country of origin, reactions to specific food fraud cases and public attitudes towards food safety associated with traceability (Cicia \& Colantuoni, 2010; Hansstein, 2014; Wendy van Rijswijk, Frewer, Menozzi, \& Faioli, 2008).

\subsection{Aims of the review}

Given the prominence of incidents of food fraud across the Europe, it is important to understand consumers' attitudes towards food fraud and their relationship with aspects of food integrity, such as authenticity, trust and risk-benefit perceptions, and perceptions of the efficacy of governance and regulatory practices that influence decision making. A systematic literature review will potentially provide important insights to food policy makers, industry stakeholders and broader society affected by food 
fraud, by identifying recommendations to enable risk communicators to improve the relevance of consumer communication practices.

This systematic review therefore seeks to understand:

- What are European consumer's perceptions and attitudes towards food fraud?

- What are the risks that European consumers associate with food fraud?

- What are the benefits that European consumers associate with demonstrating the authenticity of food?

- What steps are needed to enable those benefits to be realised?

\section{Scope and approach}

A protocol for the review was developed prior to conducting the searches and was published on PROSPERO (see CRD42018088792). Minor, in-substantive, deviations from the protocol were made.

\subsection{Search process}

Scopus, ISC Web of Knowledge and Google Scholar were searched for empirical studies published over the past 20 years i.e. 1998 onwards. In addition, reference lists of studies included were checked and key authors in the field were contacted to check for unpublished and unreturned studies (Higgins \& Green, 2011). Search terms were trialled and finalised for each database (see supplementary material A).

All returned results were exported into an EndNote library, with duplicates being removed. The results were uploaded to dedicated systematic review analysis software 'Covidence systematic review software. The results were screened according to the inclusion and exclusion criteria (Table 1), pertinent to the primary research aims. Papers were sifted in a two-stage process; first the title and abstracts were screened by three independent reviewers $\mathrm{HK}, \mathrm{BC}$ and $\mathrm{CMR}$; second, the full text of included studies were screened by the same reviewers. An overview of the search process can be found in the PRISMA flow chart (Figure 1, (Moher, Liberati, Tetzlaff, \& Altman, 2009)). Any differences between the three researchers were resolved through discussion at each stage of the analysis.

INSERT FIGURE 1 HERE

\section{INSERT TABLE 1 HERE}

Qualitative and quantitative empirical studies which investigated European consumer risk-benefit perceptions and/ or attitudes were included if they made explicit reference to food fraud or authenticity ((Spink \& Moyer, 2011), p1580). Papers that examined food traceability, or authenticity of brands/local/regional produce, with no mention of food fraud, were excluded. This deviated slightly from the published protocol as the definition of authenticity used was restricted to include the concept in conjunction with food fraud. Methodologies included quantitative surveys, focus groups and interviews, 
and studies that used experiments involving hypothetical scenarios or reactions to real world events. Studies that examined other aspects of food fraud (e.g. analytic methods aimed at detection, legal aspects of food fraud including accountability, legislation, and compliance), were excluded. Only peer reviewed studies available in English were included for pragmatic reasons.

\subsection{Assessment of risk of bias}

A quality assessment tool developed by Clark, Stewart, Panzone, Kyriazakis, and Frewer (2016) was used to quality score the empirical qualitative and quantitative methods used within the selected studies. No studies were excluded based on the quality assessment, but the scorings were taken into account during the analysis as part of the Grading of Recommendations, Assessment, Development and Evaluation (GRADE) framework (Meader et al., 2014), which assesses the overall of strength of evidence. Again, this was adapted from Clark et al. (2016), to provide a tool suitable for use in conjunction with a narrative analysis. Critical appraisal was conducted independently by three reviewers (HK, BC CMR) (see supplementary material B). Any differences in decisions related to study quality were resolved through discussion by the same authors. Although the protocol stated that reporting standards would be assessed as per the EQUATOR network guidance, this was not conducted due to overlap with the critical appraisal.

\subsection{Data synthesis}

Given the methodological diversity of studies included in the review, a narrative analysis of the data was conducted. All included studies were exported into QSR Nvivo (QSR International Pty Ltd, 2012). A thematic approach to the analysis was taken (Braun \& Clarke, 2006; Thomas \& Harden, 2008), and was used to explore the variations and relationships in the data. The analysis followed a three-stage process. First, three members of the research team (HK, BC and CR) independently undertook open coding of the papers using an inductive, grounded approach (Glaser \& Strauss, 1971). The key concepts and categories that emerged were then discussed by the same reviewers, and an initial coding framework was developed by the lead author. The second phase involved refining the coding framework, the same members of the research team independently coded a subset of papers and compared the codes against the framework. This inter-coder reliability process followed two iterations until there was agreement that the categories within the framework reflected the data. The third stage of analysis involved the same researchers coding a subset of the papers against the finalised coding framework. Any uncertainty at this final coding stage was resolved through discussion between review team members.

\section{Key findings}

The search process identified 15 studies eligible for inclusion. Table 2 presents a narrative overview of these studies. Of these, 13 were journal articles, one was a Ph.D. thesis and another a presentation. Eight studies used a quantitative methodology including; two willingness-to-pay (WTP) assessments (Agnoli, Capitello, De Salvo, Longo, \& Boeri, 2016; Doherty \& Campbell, 2014); two online surveys (Al-Tal, 2012; Barbarossa, De Pelsmacker, Moons, \& Marcati, 2016); four administered surveys (Charlebois, Schwab, 
Henn, \& Huck, 2016; Chousou, Tsakiridou, \& Mattas, 2018; Crane \& Brown, 2013; Spence et al., 2018); and one study adopted both online and administered survey methods (Yasar \& Boselli, 2015). Six studies were qualitative and included; one focus group study (Devaney, 2016); two studies which adopted an online deliberation tool (Barnett et al., 2016; Regan et al., 2015); one employed in-depth interviews (W. Van Rijswijk \& Frewer, 2012) and one a social media analysis (Tse, Zhang, Doherty, Chappell, \& Garnett, 2016). One study employed a mixed-method research design adopting focus groups and online survey methods (Salih, 2017).

All 15 studies were published after 2012. Six explored consumers' direct responses to the 2013 European horsemeat incident, while the seven remaining studies explored consumer perceptions towards the mitigation of food fraud in general, including the perceived importance of product attributes in the identification of authentic food, and attitudes and purchase intentions towards traceable food products. Six studies examined food fraud in relation to a specific food product. This primarily included beef and processed beef products, (the focus of the 2013 horsemeat incident), but also included olive oil and kebab meat products that have been previously implicated in food fraud incidents. Chicken was the focus of Doherty and Campbell (2014) due to its vulnerability to microbiological food safety contamination arising from mislabelled (typically extended) sell-by dates etc.

Three studies contained consumers from both European and non-European countries; Al-Tal (2012) has a relatively small sample of Italian compared to Iranian participants; Salih (2017) compared Kurdish and English study participants, and Yasar and Boselli (2015) compared the attitudes of Turkish consumers with a small sample of European consumers. Only the European results for these were included in the current analysis ${ }^{1}$. Prior to analysis, two studies Boeri et al. (2015), and Agnoli et al. (2016) were found to contain the same study population. Boeri et al. (2015) was excluded prior to coding as the publication was a conference paper, and the subsequently published article included more detailed information about the empirical work conducted. The conference paper was checked to see if any additional details could be provided.

In two studies (Doherty \& Campbell, 2014; Yasar \& Boselli, 2015), food fraud was assessed among a range of food safety risks. The remainder distinguished food fraud from food safety, recognising that food fraud may, but does not always, represent a risk to the safety of food.

\subsection{Quality assessment}

\footnotetext{
${ }^{1}$ We have considered Turkish consumers to be non-European given the different food regulations in Turkey
} 
relation to sampling and response rates for quantitative studies, and the role of the researcher in qualitative studies.

The GRADE assessment criteria, used to evaluate the overall strength of evidence of the returned studies, indicates an overall moderate strength of evidence (supplementary material B).

\subsection{Emergent Themes}

The thematic analysis yielded six themes (Table 3); "drivers of fraud", "consumer fraud concerns ", "trust"," responsibility", "accountability and blame", "consumer behavioural response" and "supply chain responses". Quotes from the papers to support the thematic analysis are provided in appendix C (supplementary material C).

\section{INSERT TABLE 3 HERE}

\section{Theme 1: Drivers of fraud}

Consumers' perceptions of why food fraud occurs were related to perceived food chain vulnerabilities to fraudulent activity. The complexity of supply chains and globalisation of food systems, involving multiple food chains and actors, was perceived to be the most significant factor in the proliferation of food fraud affecting a variety of food chains across Europe. Perpetrators of food fraud were perceived as legitimate food chain actors, primarily food producers and manufacturers, rather than by external actors, e.g. criminals infiltrating legitimate food systems.

Consumers were concerned about the food industry's pursuit of profit over food safety as a potential driver of fraud. Similarly, increased competition within the food industry, which resulted in lower profit margins, was also perceived as a potential driver. Food producers and manufacturers were thought to maintain and increase profits by reducing production costs through illegal means, e.g. by using inferior ingredients, adulterating ingredients using cheaper or inferior quality substitutes, and mis-labelling those ingredients.

The political, social and economic context in which food fraud occurred was considered by consumers to have provided an environment conducive to fraudulent activities. Within the UK and Ireland, and specifically in relation to the horsemeat incident, the economic downturn was perceived to have reduced the capacity of responsible agencies to conduct effective surveillance and testing.

\section{Theme 2: Responsibility, blame and accountability}

Empirical research conducted in the wake of the horsemeat incident explored consumer perceptions relating to whom responsibility, blame and accountability should be apportioned. These terms were used interchangeably by consumers. Distinctions were made between direct versus indirect responsibility. Direct responsibility for fraudulent practices was perceived as the deliberate actions of individuals within the food industry, where dishonest and deceitful activity was considered to be a part of the collective 
culture. There was recognition that blame within organisations should not be equally attributed, with responsibility falling directly to those in management positions, and with food chain workers viewed as "unwitting accomplices" to fraud. Regulatory agencies and authorities were perceived to be indirectly responsible, owing to their responsibilities for oversight of food systems, and their moral obligation to protect consumer interests. Although consumers did not consider that food authorities and regulators had colluded with industry to create an environment where fraudulent activity was permissible, moral judgements were made regarding industry failure to detect and stop adulteration. Specifically, failures to conduct adequate testing and ingredient checks were perceived to occur before the horsemeat incident, leading to criticisms that all actors, including the regulatory authorities, had not paid due attention to the potential for food fraud. The role of increased consumer demand for cheap and convenience food products was considered to have incentivised the food industry to produce inauthentic products.

\section{Theme 3: Consumer fraud concerns}

Consumers held a number of concerns in relation to fraud generally, and in relation to specific foodrelated contexts, particularly the horsemeat incident. Concerns were focused on the deliberate and deceitful nature of fraud, and intention to mislead the consumer, with malevolent activity within the food system being considered to represent the food industry's abuse of power. Actors in the food industry were perceived to collude to intentionally cover-up malpractices. Concerns were raised regarding widespread fraudulent activity, specifically within supply chains affected by fraud (e.g. beef and processed foods). Fraud concerns over specific products, e.g. beef, frequently triggered other food related concerns, such as those linked to farm animal welfare, food quality and safety.

Misleading product labelling led to reduced consumer confidence in product authenticity and quality, and the perceived integrity of producers and legislators. Consumers also expressed a belief that the practice of including unlabelled horsemeat in processed food products had been going on for many years, reducing trust in the integrity of food chains and food chain actors.

Consumers perceived that food system transparency was inadequate. Consumers indicated that they received little information about how the food they eat is produced, its origins, and about the different stakeholders involved in the supply chain. Given that this information is perceived by consumers to be available to food chain actors, information asymmetry between consumers and food chain actors is created, and consumers are unable to make informed choices regarding a product's authenticity, and other production related attributes. This suggests that more transparent communication and information provision is required in order to alleviate consumer concerns and reduce information asymmetry. Information provided by industry and institutions should address the more general and context specific concerns held by consumers, and potentially reference authenticity cues. 
301 The country of origin of products was seen as an important attribute denoting food integrity, with several

302 studies indicating that consumers had preferences for products from their own, or from other European,

303 countries.

304 Studies exploring consumers' response strategies, following the occurrence of horsemeat incident, 305 reported that consumers viewed such incidences as a breach of trust, reducing their confidence in the 306 integrity of food-chain actors and specific food supply chains. Consumers indicated that they intended to change their purchasing habits as a result.

\section{Theme 4: Consumer perceptions and attitudes following a food fraud incident}

For some consumers, perceptions of effective risk management increased their trust in food risk governance practices, demonstrating the value of the relevant government agencies, as well as justifying their budgets. Conversely, other consumers already held a positive view of food risk governance and trusted in its effectiveness. However, consumers were concerned by information asymmetry within, and transparency across, the food production process. The provision of information, as well as the credibility of the information source, influenced the attitude formation of consumers. Information sources were evaluated in terms of trustworthiness, impartiality and accuracy. European consumers were most trusting of their national government agencies, while food and drink manufacturers were the least trusted. In the wake of misleading or exaggerated media stories, it was proposed that consumer concerns could be moderated through the provision of scientific evidence and acknowledgements of uncertainties in scientific knowledge, if and/or where this might occur.

Improving transparency regarding food production processes increased consumer confidence and trust in the integrity of supply chains. Traceability systems were perceived to reduce information asymmetry between the food industry and consumers, and offered consumers reassurances regarding a product's origin, history and journey through the supply chain. In so doing, the implementation of food traceability systems increased perceptions of trust through product quality and safety assurances, particularly in situations of identification and rapid withdrawal of foods failing to meet quality and safety standards. Trust in the effectiveness of traceability systems and information provision (e.g. labelling) also increased purchase intentions of relevant products. Consumers' confidence in the trustworthiness of information was increased by access to information about the institutions guaranteeing or implementing food and ingredient traceability. The oversight of an independent government body increased trust in the effectiveness of traceability systems. However, the food industry was perceived to be able to negatively impact on the independence of food regulatory institutions and their capacity to develop and apply effective food safety measures. 
Various strategies were employed by consumers to avoid encountering fraudulent food, including their reliance on integrity cues provided by manufacturers at the point of purchase. These acted as heuristics signalling the quality and authenticity of products. One heuristic cue used by consumers was price.

337 Consumers recognised that more expensive products potentially offered quality guarantees. The need for product information to appear directly on products (and to a lesser extent at the point of sale), and for product information to be provided in a concise format with additional information provided by alternative mechanisms (i.e. barcodes, Quick Response [QR] codes or websites), was perceived by consumers to be important. This suggested that consumers generally have limited time for information processing at the point of purchase. Furthermore, different levels of information provision were required for different product types. Consumers expressed preferences for more information about processed products, or products unknown to the consumer. Product certifications denoting production standards, or reflecting geographic origin, enhanced the credibility or reliability of products, if supported by thirdparty credence information to support these claims, e.g. information about a product's place of origin, production process, or animal welfare claims. Consumers required certifications to be accompanied by contact information to guarantee the certifying institution, and a visible "logo" or seal to be included as part of the product labelling. Consumers also reported relying on sensory attributes such as appearance and taste to indicate quality and authenticity, particularly for products such as olive oil and meat.

Behavioural responses to fraud were primarily identified in relation to specific food fraud incidents, e.g. horsemeat in the beef supply chain. If a food did not meet with consumers' quality and safety expectations, consumers sought recourse through complaints to suppliers or relevant institutions, (e.g. explanations and/or compensation from the retailer), and informed government and consumer organisations that a product had been subject to fraud. Complaining directly to the producer was the least preferred option. Changes in consumption behaviours and purchasing habits in response to the detection of fraud within a food chain were also observed. Such actions included brand and product switching (i.e. purchasing fish or vegetarian options to replace meat), wider information searching prior to purchase (i.e. via internet searches) and/or avoidance of specific products (i.e. highly processed meats or convenience type foods), or retailers that were associated with food fraud incidents. Where possible, consumers attempted to purchase food from trusted suppliers, e.g. in the case of meat, consumers purchased from local butchers. Buying from retailers included in shorter supply chains allowed consumers to ask questions and receive personal reassurances from food chain actors regarding the quality and origin of products. This represented an important means of reducing perceived risks associated with food fraud. For other consumers, restricting the purchase of products to those that had been made in their home country was used as a means of reducing the possibility of encountering food that had been adulterated. 
The literature suggests that consumers require food chain actors to take both reactive and proactive measures to mitigate food fraud. Consumers required increased transparency throughout the supply chain in order to reduce information asymmetry, with consumers reporting that they would be willing to pay a price premium for traceable products. In the wake of a food fraud incident, consumers required the provision of transparent information, regardless of expert uncertainties regarding the nature and extent of the risk and whether it had occurred. They also expected remedial actions to be applied following the incident, such as open apologies from the food business operators and agencies responsible for the governance of food systems, and information about the preventative actions taken by both parties. Penalties and sanctions, including custodial sentences for those caught perpetrating fraudulent acts, were considered justifiable and served as deterrents to other potential food fraudsters. They were also considered to be an important mechanism for rebuilding consumer confidence in the governance of food systems. In accordance with the principles of good governance practices, consumers thought that they should be more engaged in the development of policies via consultative mechanisms that support dialogue between policy makers and the public. The published literature on public perceptions of food fraud was shown to be relatively recent, with all studies included in this review published from 2012 onwards, and 11 of the studies being published after 2015. Six were conducted in direct response to the horsemeat adulteration incident that affected the European beef supply chain in 2013, with no other specific incidents being considered (e.g. The 2012 Czech Republic spirit fraud), which may have influenced the analysis, as the horsemeat incident was not associated with food safety concerns in a technical sense. The review did not cover the time period for the major food fraud incidents of the 1980s (Spanish olive oil and Austrian wines) although an additional literature search indicates that no research papers focused on public perceptions and attitudes published in English were available prior to the time period which was covered by the systematic review reported here.

The recent increase in research interest on food authenticity and consumer perceptions may also reflect the growth in media and social attention on food fraud, including the increased role played by social media in information dissemination. There is no evidence to suggest that this reflects an increase in food fraud incidence. This may, however, reflect increased detection through improvements to surveillance in Europe, including the introduction of the FFN. While food fraud has always posed a threat to the integrity of European food chains, apart from developing detection methodology, it has only relatively recently been the focus of academic study. This may, in part, signal a lack of clarity regarding the definitions of food fraud and food safety, leading to fraud-related incidents with public and environmental health related outcomes being subsumed into the general analysis of food safety incidents. Alternatively, it is 
only recently that methods of analysis have been developed to detect (some) authenticity characteristics (Esteki et al., 2019) This might also reflect key changes in food policy governance that was instituted in the late 2000's across Europe, i.e. the demarcation between food safety and food production responsibilities. Further transnational research exploring consumer perceptions and attitudes towards fraud in food systems is warranted, not least because the results are likely to inform priorities in regulatory and policy development.

Six themes relevant to our understanding of consumer attitudes towards food fraud emerged from the thematic analysis. Given the limitations of the (English peer reviewed) literature available, the results suggest that the public are concerned about food fraud, related to perceptions of intentional deception on the part of fraudsters, and the impact that this has had upon consumers' abilities to make informed decisions about the food that they purchase and consume. The findings contrast those of empirical research conducted regarding the attitudes of Chinese consumers (Kendall et al., 2019; Kendall et al., 2018), with results suggesting that European consumers did not appear to perceive food fraud to represent such a significant risk to the safety of food as has been the case in other regions (e.g. China). This conclusion may be a consequence of the time period in which the literature review was conducted, insomuch as research papers included in the review were dominated by empirical investigation of the horsemeat adulteration incident, on which the consumer research identified in this review has focused, and which was widely reported to carry only minor risks to food safety or public health. Thus, it is predicted attitudinal responses may vary according to the countries affected by specific fraud incidents studied, and the academic tradition of assessing risk perceptions and related attitudes within those countries. Thus, the extent to which the review can be representative of European consumer views is therefore questionable.

Taking the case of the Czech Republic spirit fraud case, there is evidence that the incident has opened up a range of alcohol consumption issues in Czech society associated with the health risks of alcohol more generally (SZU, no date), and has had a direct impact on the alcohol consumption habits of Czech citizens, where consumption of spirits had declined dramatically (Přibylová, 2014), although there is no perceptual or attitudinal analysis available to explain this decline. Unsurprisingly, the incident was associated with extensive media reporting of the risks and its underlying causes (Kolátorová, 2016), including a television film in Czech, "Methanol", which detailed the course of events (Aktualne, 2018). The methanol affair has financially damaged both small and large retailers and distributors, who have also suffered a loss of consumer confidence in their products in addition to significant financial losses. Measures taken against illegal production and distribution of alcohol have to some extent mitigated consumer concerns, and Czech citizens are more interested in the origin and brand of alcohol than before the occurrence of the incident (Hajslova, personal communication). The lack of English language publications (both in peer reviewed journals and in the English language media) may be interpreted as a "construal" effect, such 
that people mentally construe objects that are psychologically near in terms of low-level, detailed, and contextualized features, whereas if they perceive the "threat" is located at a distance they construe the same objects or events in terms of high-level, abstract, and stable characteristics (Trope, Liberman, \& Wakslak, 2007). Thus, the social scientific and media interest in this particular incident outside of the Czech Republic was limited. Similarly, as noted in the introduction, Italy is the European country with the highest number of food fraud incidents reported. However, peer reviewed journal articles on the impacts on public perceptions about, and attitudes towards, food fraud and authenticity were not identified. Further investigation examining local language publications including the grey literature may indicate greater availability of information. For example, if the incidents are linked to fraudulent PDO/PGI products, then there is potential for industry/organisation reports to detail responses rather than academic articles.

Consumer trust and confidence, particularly in the food industry, was shown to be negatively affected following the occurrence of a food fraud incident, with perceptions that intentional deceit was intended on the part of supply chain actors undermining consumer confidence in the information they provide. There was evidence that European consumer confidence could be restored relatively quickly if appropriate remedial action was taken to mitigate quality or food safety problems within supply chains. Food industry actors were blamed for the occurrence of food fraud. While the role of regulatory organisations in the prevention of fraud was noted, these institutions were not considered by consumers to have colluded with industry in perpetrating such acts. However, there appeared to be some discrepancy in consumer opinion as to whether the detection of fraud in food systems by regulatory authorities was evidence of their negligence, or whether it signalled vigilance and effectiveness of their surveillance activities. Independent of this, consumers required immediate corrective actions to be taken by all stakeholders within the food system if fraud was detected.

Past incidents and consistent media reports of malevolence in the food chain have potential to undermine or promote consumer confidence in food systems, trust in food industry and institutional actors and their actions, and in the food system as a whole. Societal discussion about an incident, in particular media reporting, may amplify (increase) and subsequently attenuate (reduce) public perceptions of not only the risks but other salient features of the incident such as attribution of blame and institutional controllability (Kasperson et al., 1988). One consequence may be that consumers will seek alternative products to those associated with the affected supply chain, supplier, or region or country of production (Böcker, 2002; Jin, Zhang, \& Xu, 2017), or question the motives of those tasked with consumer protection.

Consumer reactions have also been shown to be fuelled by feelings of deceit and betrayal by stakeholders in the food chain, the way in which events are portrayed by the media, and the perceived efficacy of political responses and fraud mitigation actions (Kasperson, Jhaveri, \& Kasperson, 2013; Regan 
et al., 2015), together understood as "social amplification of risk". Such effects have been documented in relation to other food safety incidents (e.g. genetically modified foods, (Frewer, Miles, \& Marsh, 2002) BSE (Frewer \& Salter, 2002; Lewis \& Tyshenko, 2009). In the time period evaluated by this research, the major incident which was subject to an empirical analysis of consumer attitudes was that of horsemeat in the beef supply chain. The results of the thematic analysis would suggest that social amplification effects had occurred in relation to concerns about the security and governance of the beef supply chain, but that, in the absence of widespread reporting about major public health threats, that social amplification of risk (perceptions) were not as great as has been the case for other high profile food fraud and food risk incidents. The results of the systematic review as applied to the horsemeat incident would be in line with the social amplification of risk framework, which suggests that the content of societal discourse about a specific issue influences perceptions and attitudes, as does the absolute levels and "availability" of this discourse. However, evidence about attenuation (or reduction) of these same concerns was not provided, possibly because information about mitigatory actions were not reported, the timeframe of analysis was too brief for attenuation to occur, or that attenuation did not result as a consequence of institutional actions and societal discourse about these.

Consumers perceived fraud to be perpetrated by legitimate food chain actors, primarily food producers and manufacturers. This is consistent with evidence about which actors have perpetrated identified cases of fraud in Europe. However, food fraud can also be committed by external actors, e.g. criminals infiltrating legitimate food systems, who have been acknowledged to be fraud perpetrators within the wider food fraud literature (see inter alia (Elliott, 2014; Lord et al., 2017; van Ruth, Luning, Silvis, Yang, \& Huisman, 2018; van Ruth et al., 2017). This was not identified as important by consumers in the research reviewed here, although questions that aimed to assess which actors were the perpetrators of fraudulent activities were not explicitly included within the studies reviewed.

Consumers face a situation of information asymmetry, whereby they are required to trust the information provided to them by the food industry and organisations involved in its regulation regarding the integrity of food that they purchase and consume. There is evidence that consumers question the integrity of information that they receive, and require increased transparency across the food system. Traceability systems that allow food to be tracked and traced throughout all stages of production were viewed by consumers as an important mechanism for verifying the origin of food products, and in addition helped to provide consumers with authenticity assurances. The development of multiple information delivery mechanisms, including on-product information linked to product origin and traceability systems, may facilitate communication with consumers. Information channels including barcodes, QR codes and online material can provide more detailed information about a product's origins and journey through the supply chain. Technological advances in tracking and tracing may further 
reassure consumers about the authenticity of products, with blockchain technology in particular thought to provide a particularly secure and transparent means of guaranteeing authenticity (Galvez et al., 2018).

Consistent with the findings of Chinese consumer research (see (El Benni et al., 2019; Kendall et al., 2019; Kendall et al., 2018), the results of the review suggested that consumers in Europe had taken measures to mitigate the risks associated with food fraud. Product avoidance, brand, retailer switching, and product substitution were the most commonly identified consumer responses to fraud and/or the threat of fraud within food supply chains. For industry this presents a significant economic motive to ensure that production is compliant with European food standards, and that appropriate measures are taken to reduce potential vulnerabilities to fraud within food supply chains (see Esteki et al. (2019) for a summary of these), which may or may not originate from actors within these chains. Moreover, it also signals the importance of communication with consumers regarding measures taken to protect their interests in relation to the integrity of food and reduce information asymmetries between consumers and industries

519 (Esteki et al., 2019).

\section{Summary}

521 Consumer perceptions of and attitudes towards food fraud represents a relatively new addition to the consumer risk literature. Food fraud is of concern to the European public, and consumer concern has increased following highly publicised cases, such as the horsemeat incident. The findings of this systematic review imply that reassurances surrounding product origin can engender consumer trust, as can demonstrating product traceability within the supply chain. Providing evidence of effective surveillance, and regulatory enforcement, need to be embedded in communication with the public. The adoption of theoretically underpinned research that links risk perceptions and attitudes to (different) food fraud incidents is needed, and would allow for comparisons across different consumer characteristics and information needs. More research is also required to study consumer reactions to food fraud incidents across Europe, and to assess the long term impacts on consumer confidence of interventions designed to combat food fraud on consumer confidence.

\section{Strengths and weaknesses of the review}

533 This review has identified empirical research exploring European consumers' attitudes and perceptions of 534 food fraud. The 2013 horsemeat incident prompted British, Irish and Dutch researchers to examine both the origin of the fraud incident perpetration and consumers' responses. However, the results of this research may not be representative of European consumer perceptions of, and attitudes to, food fraud more generally, as the research was linked to a specific incident with limited public or environmental health impacts. In addition, this review included only studies published in English. As noted, publications that may have explored consumer perceptions in relation to the Eastern European spirit adulteration incident, and others that were published in European languages other than English, were excluded from this review. Moreover, it is possible that there is additional inaccessible literature such as company 
reports which may have provided additional information about consumer perceptions and attitudes. Thus, it is not possible to generalise the findings of this paper to describe the attitudes of all European consumers in response to all types of fraud. There is, therefore, a need to conduct consumer attitudinal research as and when food incidents occur, as consumer perceptions and attitudes are likely to be shaped by recently occurring events presented in a "crisis" context. Future research might also usefully consider exploring the differences in consumer reactions to different food fraud incidents. Finally, the time period in which the research was conducted (20 years from 1998) would eliminate the possibility of including research on food fraud incidents which have occurred prior to 1998, which may be particularly relevant if social amplification and attenuation of risk perceptions have occurred, i.e. increased food risk perception may be temporary and time-bound, congruent to the societal discourse associated with a risk event. The time frame for the review was based on the assumption that consumer research in relation to food fraud is comparatively recent, in line with institutional recognition that there is a need to detect and mitigate it.

\section{$7 \quad$ References}

Agnoli, L., Capitello, R., De Salvo, M., Longo, A., \& Boeri, M. (2016). Food fraud and consumers' choices in the wake of the horsemeat scandal. British Food Journal, 118(8), 1878-1893. doi: 10.1108/bfj-04-20160176

Aktualne. (2018). "Tekutá smrt" mohla v Česku zabít 150 tisíc lidí. Kvůli lidské blbosti, říkají tvưrci filmu Metanol. Retrieved 24th April 2019, from https://magazin.aktualne.cz/televize/film-metanol-ceskatelevize-metanolova-afera/r 6a53f69243cc11e8a79a0cc47ab5f122/?redirected=1554673389

Al-Tal, S. M. S. (2012). Modeling information asymmetry mitigation through food traceability systems using partial least squares. Electronic Journal of Applied Statistical Analysis, 5(2), 237-255.

\section{Barbarossa, C., De Pelsmacker, P., Moons, I., \& Marcati, A. (2016). The influence of country-of-origin} stereotypes on consumer responses to food safety scandals: The case of the horsemeat adulteration. Food quality and preference, 53, 71-83. doi: https://doi.org/10.1016/j.foodqual.2016.05.015

Barnett, J., Begen, F., Howes, S., Regan, A., McConnon, A., Marcu, A., ... Verbeke, W. (2016). Consumers' confidence, reflections and response strategies following the horsemeat incident. Food Control, 59, 721730.

BBC News. (2017). Fipronil egg scandal: What we know. Retrieved 29th November 2018, from https://www.bbc.co.uk/news/world-europe-40878381

Böcker, A. (2002). Consumer response to a food safety incident: exploring the role of supplier differentiation in an experimental study. European Review of Agricultural Economics, 29(1), 29-50. 
Boeri, M., Brown, H., Longo, A., Agnoli, L., De Salvo, M., Vrontis, D., . . Tsoukatos, E. (2015). AUTHENTICITY AND FOOD SAFETY IN READY TO HEAT LASAGNE: AN EVALUATION AFTER THE 'HORSE MEAT SCANDAL'.

Braun, V., \& Clarke, V. (2006). Using thematic analysis in psychology. Qualitative research in psychology, 3(2), 77-101.

Brooks, S., Elliott, C. T., Spence, M., Walsh, C., \& Dean, M. (2017). Four years post-horsegate: an update of measures and actions put in place following the horsemeat incident of 2013. npj Science of Food, 1(1), 5.

Charlebois, S., Schwab, A., Henn, R., \& Huck, C. W. (2016). Food fraud: An exploratory study for measuring consumer perception towards mislabeled food products and influence on self-authentication intentions. Trends in Food Science \& Technology, 50, 211-218.

Chousou, C., Tsakiridou, E., \& Mattas, K. (2018). Valuing Consumer Perceptions of Olive Oil Authenticity. Journal of International Food and Agribusiness Marketing, 30(1), 1-16. doi: 10.1080/08974438.2017.1382418

Cicia, G., \& Colantuoni, F. (2010). Willingness to pay for traceable meat attributes: a meta-analysis. International Journal on Food System Dynamics, 1(3), 252-263.

Clark, B., Stewart, G. B., Panzone, L. A., Kyriazakis, I., \& Frewer, L. J. (2016). A systematic review of public attitudes, perceptions and behaviours towards production diseases associated with farm animal welfare. Journal of Agricultural and Environmental Ethics, 29(3), 455-478.

Covidence systematic review software. Melbourne, Australia.: Veritas Health Innovation. Retrieved from www.covidence.org

Crane, J., \& Brown, G. (2013). FSA-Consumer Attitudes to Towards the Horse Meat Contamination Issue.

De Jonge, J., Frewer, L., Van Trijp, H., Jan Renes, R., De Wit, W., \& Timmers, J. (2004). Monitoring consumer confidence in food safety: an exploratory study. British Food Journal, 106(10/11), 837-849.

Devaney, L. (2016). Good governance? Perceptions of accountability, transparency and effectiveness in Irish food risk governance. Food Policy, 62, 1-10. doi: 10.1016/j.foodpol.2016.04.003

Doherty, E., \& Campbell, D. (2014). Demand for safety and regional certification of food Results from Great Britain and the Republic of Ireland. British Food Journal, 116(4), 676-689. doi: 10.1108/bfj-10-20110266 
604 attributes and consumer attitudes affecting the preferences for infant milk formula in China-A latent 605 class approach. Food quality and preference, 71, 25-33.

Elliott, C. (2014). Elliott Review Into the Integrity and Assurance of Food Supply Networks-Final Report: A National Food Crime Prevention Framework: Department for Environment, Food \& Rural Affairs Food Standards Agency.

Esteki, M., Regueiro, J. \& Simal-Gándara, J. (2019). Tackling Fraudsters with Global Strategies to 610 Expose Fraud in the Food Chain. Comprehensive Reviews in Food Science and Food Safety, 18(2), $611425-440$. European Commission. (2010). 2010 Eurobarometer survey report on risk perception in the EU. European Commission. (2017a). The EU Food Fraud Network and the System for Administrative Assistance \& Food Fraud. Annual report 2017. European Commission. (2017b). Fipronil in eggs. European Commission. (2017c). Fipronil in eggs: Factsheet - December 2017. 5th December 2018, from https://ec.europa.eu/jrc/en/publication/brochures-leaflets/fipronil-eggs-factsheet-december-2017 European Commission. (2019). Knowledge centre for food fraud and quality. Retrieved 24th April 2019, from https://ec.europa.eu/knowledge4policy/food-fraud-quality_en European Commission. (no date). The EU Food Fraud Network. Retrieved from https://ec.europa.eu/food/safety/food-fraud/ffn_en Europol. (2017). EUR 230 MILLION WORTH OF FAKE FOOD AND BEVERAGES SEIZED IN GLOBAL OPSON OPERATION TARGETING FOOD FRAUD. 5th December 2018, from https://www.europol.europa.eu/newsroom/news/eur-230-million-worth-of-fake-food-and-beveragesseized-in-global-opson-operation-targeting-food-fraud Food Standards Agency. (2017). National Food Crime Unit. Retrieved 17th April 2019, from https://www.food.gov.uk/about-us/national-food-crime-unit

629 Risk/benefit communication about food-a systematic review of the literature. Critical reviews in food 630 science and nutrition, 56(10), 1728-1745. case of BSE. Science and public policy, 29(2), 137-145. 
Frewer, L. J., Howard, C., Hedderley, D., \& Shepherd, R. (1996). What determines trust in information about food-related risks? Underlying psychological constructs. Risk analysis, 16(4), 473-486.

Frewer, L. J., Miles, S., \& Marsh, R. (2002). The media and genetically modified foods: evidence in support of social amplification of risk. Risk Analysis: An International Journal, 22(4), 701-711.

Galvez, J.F., Mejuto, J.C. \& Simal-Gandara, J. (2018). Future challenges on the use of blockchain for food traceability analysis. TrAC Trends in Analytical Chemistry, 107, 222-232.

Glaser, B. S., \& Strauss, A. (1971). The discovery of grounded theory. . New York.

Grayson, K., \& Martinec, R. (2004). Consumer perceptions of iconicity and indexicality and their influence on assessments of authentic market offerings. Journal of Consumer Research, 31(2), 296-312.

Hansen, J., Holm, L., Frewer, L., Robinson, P., \& Sandøe, P. (2003). Beyond the knowledge deficit: recent research into lay and expert attitudes to food risks. Appetite, 41(2), 111-121.

Hansstein, F. V. (2014). Consumer knowledge and attitudes towards food traceability: a comparison between the European Union, China and North America. Paper presented at the 2014 International conference on food security and nutrition IPCBEE.

Higgins, J. P., \& Green, S. (2011). Cochrane handbook for systematic reviews of interventions 5.1. 0. The Cochrane Collaboration, 33-49.

Hobbs, J. E., \& Goddard, E. (2015). Consumers and trust. Food Policy, 52, 71-74.

Jin, S., Zhang, Y., \& Xu, Y. (2017). Amount of information and the willingness of consumers to pay for food traceability in China. Food Control, 77, 163-170.

Kasperson, R., Jhaveri, N., \& Kasperson, J. X. (2013). Stigma and the social amplification of risk: Toward a framework of analysis. In J. Flynn, P. Slovic, \& H. Kunreuther (Eds.), Risk, media and stigma. Understanding public challenges to modern science and technology (pp. 9-27): Routledge.

Kasperson, R. E., Renn, O., Slovic, P., Brown, H. S., Emel, J., Goble, R., . . Ratick, S. (1988). The social amplification of risk: A conceptual framework. Risk analysis, 8(2), 177-187.

Kendall, H., Kuznesof, S., Dean, M., Chan, M.-Y., Clark, B., Home, R., . . Brereton, P. (2019). Chinese consumer's attitudes, perceptions and behavioural responses towards food fraud. Food Control, 95, 339351.

Kendall, H., Naughton, P., Kuznesof, S., Raley, M., Dean, M., Clark, B., . . Zhong, Q. (2018). Food fraud and the perceived integrity of European food imports into China. PLOS One, 13(5), e0195817. 
662

663

664

665

666

667

668

669

670

671

672

673

674

675

676

677

678

679

680

681

682

683

684

685

686

687

688

689

690

Kolátorová, L. (2016). Methanol affair in the czech media (Metanolová aféra v českých médiích).

(Masters), Charles University Prague. Retrieved from

https://is.cuni.cz/webapps/zzp/detail/139274/,\%20in

Lewis, R. E., \& Tyshenko, M. G. (2009). The impact of social amplification and attenuation of risk and the public reaction to mad cow disease in Canada. Risk Analysis: An International Journal, 29(5), 714-728.

Liu, M. J., Yannopoulou, N., Bian, X., \& Elliott, R. (2015). Authenticity perceptions in the Chinese marketplace. Journal of Business Research, 68(1), 27-33.

Lobb, A. (2005). Consumer trust, risk and food safety: A review. Food Economics-Acta Agriculturae Scandinavica, Section C, 2(1), 3-12.

Lord, N., Flores Elizondo, C. J., \& Spencer, J. (2017). The dynamics of food fraud: The interactions between criminal opportunity and market (dys) functionality in legitimate business. Criminology \& Criminal Justice, 17(5), 605-623.

Luhmann, N. (2000). Familiarity, confidence, trust: Problems and alternatives. Trust: Making and breaking cooperative relations, 6, 94-107.

Lyon, F., \& Porter, G. (2007). Market institutions, trust and norms: exploring moral economies in Nigerian food systems. Cambridge Journal of Economics, 33(5), 903-920.

Martinez, M. G., \& Epelbaum, F. B. (2011). The role of traceability in restoring consumer trust in food chains Food Chain Integrity (pp. 294-302): Elsevier.

Meader, N., King, K., Llewellyn, A., Norman, G., Brown, J., Rodgers, M., . . Stewart, G. (2014). A checklist designed to aid consistency and reproducibility of GRADE assessments: development and pilot validation. Systematic reviews, 3(1), 82.

Meijboom, F. L., Visak, T., \& Brom, F. W. (2006). From trust to trustworthiness: Why information is not enough in the food sector. Journal of Agricultural and Environmental Ethics, 19(5), 427-442.

Moher, D., Liberati, A., Tetzlaff, J., \& Altman, D. G. (2009). Preferred reporting items for systematic reviews and meta-analyses: the PRISMA statement. Annals of internal medicine, 151(4), 264-269.

Nakyinsige, K., Man, Y. B. C., \& Sazili, A. Q. (2012). Halal authenticity issues in meat and meat products.

Meat Science, 91(3), 207-214.

Premanandh, J. (2013). Horse meat scandal-A wake-up call for regulatory authorities. Food Control, 34(2), 568-569. 
Přibylová, E. (2014). Effect of methanol affair on patterns of alcohol use in the Czech Republic: online survey (Vliv metanolové kauzy na vzorce užívání alkoholu v ČR: internetový průzkum). (Masters), Charles University Pragrue.

QSR International Pty Ltd. (2012). Nvivo qualitative data analysis software (Vol. Version 10).

Regan, Á., Marcu, A., Shan, L. C., Wall, P., Barnett, J., \& McConnon, Á. (2015). Conceptualising responsibility in the aftermath of the horsemeat adulteration incident: an online study with Irish and UK consumers. Health, Risk and Society, 17(2), 149-167. doi: 10.1080/13698575.2015.1030367

Salih, S. M. (2017). Authenticity and Quality of Muscle Foods: Assessing Consumer Trust and Fraud Detection Approaches.

Snellings, W. M., McMartin, K. E., Banton, M. I., Reitman, F., \& Klapacz, J. (2017). Human health assessment for long-term oral ingestion of diethylene glycol. Regulatory Toxicology and Pharmacology, 87, S1-S20.

Spence, M., Stancu, V., Elliott, C. T., \& Dean, M. (2018). Exploring consumer purchase intentions towards traceable minced beef and beef steak using the Theory of Planned Behavior. Food Control.

Spink, J., \& Moyer, D. C. (2011). Defining the public health threat of food fraud. Journal of Food Science, 76(9).

SZU. (no date ). Metanolová aféra: Jaká je role alkoholu ve výživě člověka? . Retrieved 24th April 2019, from http://www.szu.cz/metanolova-afera-jaka-je-role-alkoholu-ve-vyzive-cloveka

Thankappan, S. (2016). European food regulation and accountability: the interplay of influences shaping the new regulatory terrain Ethics, Law and Society (pp. 81-116): Routledge.

Thomas, J., \& Harden, A. (2008). Methods for the thematic synthesis of qualitative research in systematic reviews. BMC Medical Research Methodology, 8(1), 45.

Trope, Y., Liberman, N., \& Wakslak, C. (2007). Construal levels and psychological distance: Effects on representation, prediction, evaluation, and behavior. Journal of consumer psychology, 17(2), 83-95.

Tse, Y. K., Zhang, M. H., Doherty, B., Chappell, P., \& Garnett, P. (2016). Insight from the horsemeat scandal Exploring the consumers' opinion of tweets toward Tesco. Industrial Management \& Data Systems, 116(6), 1178-1200. doi: 10.1108/imds-10-2015-0417

Van Rijswijk, W., \& Frewer, L. J. (2012). Consumer needs and requirements for food and ingredient traceability information. International Journal of Consumer Studies, 36(3), 282-290. doi: 10.1111/j.14706431.2011.01001.x 
van Rijswijk, W., Frewer, L. J., Menozzi, D., \& Faioli, G. (2008). Consumer perceptions of traceability: A cross-national comparison of the associated benefits. Food Quality and Preference, 19(5), 452-464. doi: http://dx.doi.org/10.1016/j.foodqual.2008.02.001 van Ruth, S., Luning, P., Silvis, I., Yang, Y., \& Huisman, W. (2018). Differences in fraud vulnerability in various food supply chains and their tiers. Food Control, 84, 375-381. in Food Science \& Technology, 67, 70-75.

Yasar, S., \& Boselli, E. (2015). Perception and awareness of the European Union food safety framework. Italian Journal of Food Science, 27(1), 126-134.

Zakharov, S., Pelclova, D., Urban, P., Navratil, T., Diblik, P., Kuthan, P., . . Vaneckova, M. (2014). Czech mass methanol outbreak 2012: epidemiology, challenges and clinical features. Clinical toxicology, 52(10), 1013-1024. schemes: evidence from Beijing, China. Journal of Cleaner Production, 134, 269-279.

ESTEKI, M., REGUEIRO, J. \& SIMAL-GÁNDARA, J. 2019. Tackling Fraudsters with Global Strategies to Expose Fraud in the Food Chain. Comprehensive Reviews in Food Science and Food Safety, 18, 425-440.

GALVEZ, J. F., MEJUTO, J. C. \& SIMAL-GANDARA, J. 2018. Future challenges on the use of blockchain for food traceability analysis. TrAC Trends in Analytical Chemistry, 107, 222-232. 